\title{
Neonatal tetanus treated with high dosage diazepam
}

\author{
B. H. KHOO, E. L. LEE, AND K. L. LAM \\ From the Department of Paediatrics, University Hospital, University of Malaya, Kuala Lumpur
}

SUMMARY The combination of continuous intravenous infusion of diazepam $(20-40 \mathrm{mg} / \mathrm{kg}$ per day) and intragastric phenobarbitone (10-15 mg/kg per day in 4 divided doses) was used to treat 19 cases of neonatal tetanus. Mortality was $2 / 19(11 \%)$. This regimen was considered to have reduced the mortality and the need for artificial ventilation. The main side effects encountered were severe drowsiness, coma, and apnoeic episodes which were reversible when the level of diazepan was reduced.

Neonatal tetanus has a high mortality and is a serious problem in developing countries. Diazepam has powerful muscle relaxing and anticonvulsant properties and has been used in conventional dosage $(2-13 \mathrm{mg} / \mathrm{kg}$ per day) to treat neonatal tetanus, but this has had little effect on mortality (Hendrickse and Sherman, 1966; Oduori, 1974). We report our experience with high dose diazepam in the management of neonatal tetanus.

\section{Patients and methods}

Nineteen consecutive cases of neonatal tetanus were admitted to this hospital between January 1974 and June 1977. The diagnosis was clinical, any neonate presenting with at least 3 of the following was included in the study: trismus, risus sardonicus, muscular rigidity, and spasms of voluntary muscles. Lumbar puncture was performed and blood glucose, calcium, and magnesium levels were determined in most patients. The severity of the illness was graded according to the criteria of Patel and Joag (1959), , one point being awarded to each of the following: (a) inability to suck, (b) presence of muscular spasms, (c) rectal temperature $\geqq 38^{\circ} \mathrm{C}$ within 24 hours of admission, (d) incubation period $\leq 7$ days, (e) onset rof spasms occurring within 48 hours after the first symptom. All the patients had severe tetanus (grades 4 and 5).

General care. On admission a peripheral intravenous infusion with $5 \%$ dextrose in $0.18 \%$ saline was set up. An initial slow bolus IV injection of $2 \mathrm{mg}$ increasing to $10 \mathrm{mg}$ diazepam was administered to relieve muscular spasms and rigidity. The neonate

Received 31 January 1978 was nursed in an incubator in the open paediatric ward; the pulse and respiratory rate, colour, and frequency and severity of muscular spasms were closely monitored. Particular care was paid to clearing the nasopharynx of secretions.

Antibiotics, tetanus antitoxin, and toxoid. The umbilical cord, if infected, was excised and the umbilicus cleaned with hydrogen peroxide and surgical spirit. All patients received 1500 to 5000 units of equine antitetanus serum, and IV crystalline penicillin (100 000 units $\mathrm{kg} /$ per day) was given for 7 days. Active immunisation was started before discharge.

Feeding. During the first 24 hours the daily fluid and electrolyte requirements were administered intravenously as the risk of aspiration from uncontrolled spasms was greatest during this period. Thereafter, nasogastric milk feeding was introduced and the amount gradually increased. In most cases nasogastric feeding was fully established by the 5th to 7th day, the IV drip being continued only for the administration of drugs. However in 7 patients nasogastric feeding was not tolerated and nutrition was provided by peripheral intravenous hyperalimentation.

Sedation. Muscle relaxation and sedation were achieved by continuous IV infusion of high dose diazepam (20-40 mg/kg per day) and intragastric phenobarbitone $(10-15 \mathrm{mg} / \mathrm{kg}$ per day in 4 divided doses). The initial total daily maintenance dose of diazepam was $20 \mathrm{mg} / \mathrm{kg}$ and this could be increased gradually to a maximum of $40 \mathrm{mg} / \mathrm{kg}$ until spasms were controlled. Additional bolus injections of diazepam (5-10 mg) were administered if spasms 
were severe and frequent; but these were not given more than 4 times in 24 hours. Once spontaneous spasms had ceased for at least 48 hours, the dose of diazepam was reduced every third day by approximately $10 \%$ of the previous dose. If dosage reduction was attempted too rapidly, spontaneous spasms recurred and subsequent control was sometimes difficult. Diazepam was given via the nasogastric tube when the spasms were controlled and nasogastric feeding had been established; this was usually achieved after 5 to 10 days of intravenous therapy. A few patients had hiccups but these were effectively controlled by 2 to $5 \mathrm{mg}$ IV chlorpromazine.

Total paralysis and intermittent positive pressure ventilation (IPPV). This was instituted when conservative drug therapy at maximum dosage had failed to control severe spasms. $7(37 \%)$ out of 19 required this treatment. Except for Case 6, IPPV was started within 24 hours of admission. All previous sedatives were discontinued and tubocurare was used to provide muscle relaxation. Details of the anaesthetic care have been reported (Ganendran, 1974).

\section{Results}

17 patients survived the illness and 2 died while $\overline{\bar{A}}$ IPPV from tension pneumothorax and extensic bronchopneumonia (Table). The mortality rate was thus $11 \%$. The average time in hospital was 40 days. Muscle rigidity persisted for about 5 7 weeks from onset of illness. At follow-up, $\frac{\overrightarrow{\sigma^{2}}}{2}$ patients were found to have neurological deficf. One of these (Case 5) was on the respirator for 65 days during which time he developed nun $\vec{\oplus}$ erous episodes of tension pneumothorax, bronch $\theta^{-}$ pneumonia, cyanosis, and bradycardia. Subsequent庶 he developed subglottis stenosis and at follow-w examination at 2 years of age he was found to floppy with microcephaly and mental retardatioge The other patient (Case 14) had multiple episodes of severe spasms with cyanosis, but was never did IPPV. At 3 years of age this child was found to have cerebral palsy with left hemiparesis, microcephalo and mental retardation. The neurological deficit in these 2 patients probably resulted from cerebrfol hypoxia suffered during severe spasms and, in Case from numerous episodes of tension pneumothorax

Table 1 Severity of neonatal tetanus, mode of treatment, and outcome

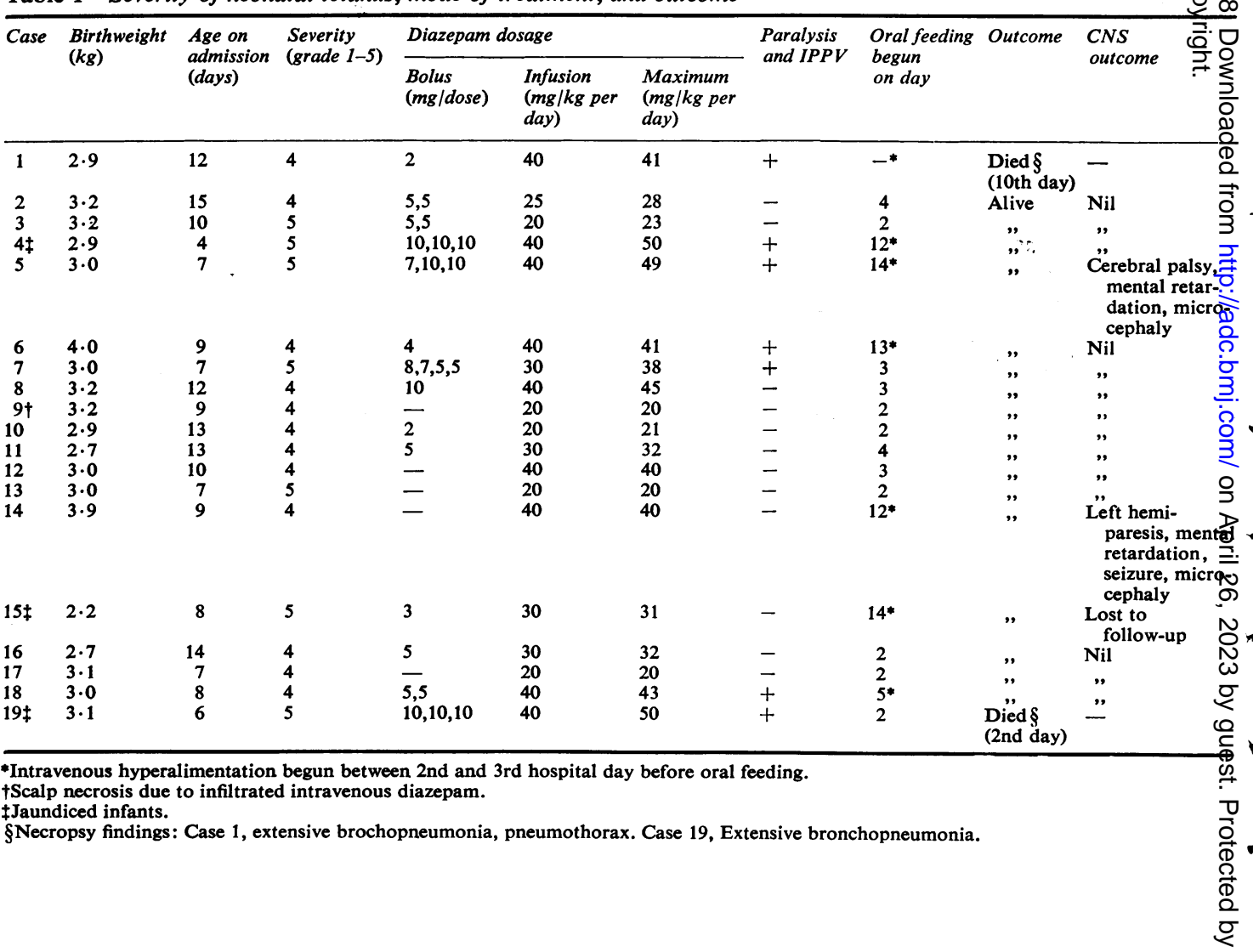


and cyanosis while on IPPV. The neurological sequelae seem unlikely to be the result of treatment with diazepam because these children were still having frequent muscle spasms in spite of the high dose of diazepam.

\section{Discussion}

Diazepam is a potent tranquilliser, anticonvulsant, and muscle relaxant. Although the site and mechanism of its action are still incompletely understood, it has been shown to block spinal reflexes in anaesthetised cats (Randal et al., 1961). Hendrickse and Sherman (1966) first reported the use of oral diazepam (up to $4.4 \mathrm{mg} / \mathrm{kg}$ per day) in a controlled study of 104 cases of neonatal tetanus. They concluded that although the mortality rate $(55 \%)$ was unaffected by diazepam, it was of value in relaxing tonic muscle spasms; moreover it was relatively free of unpleasant side effects or toxicity. There has been only one report of the use of high dose diazepam $(40 \mathrm{mg} / \mathrm{kg}$ per day) in the successful treatment of a patient with neonatal tetanus (Femi-Pearse, 1966).

From 1969 to 1973 , we treated 43 cases of neonatal tetanus $(89 \%$ of whom were grade 4 and 5 severity) with conventional dose IV diazepam (2-10 $\mathrm{mg} / \mathrm{kg}$ per day divided into 4 doses) and nasogastric phenobarbitone $(5-15 \mathrm{mg} / \mathrm{kg}$ per day divided into 4 doses). The result was disappointing as $77 \%$ of those patients subsequently required IPPV because of failure to control the spasms (Lee et al., 1978). In the present series, only $7(37 \%)$ of 19 patients required IPPV. The severity of the disease in the present group was similar to the 1969-73 group (100 and $89 \%$ respectively falling into the severe grades). In our experience, increasing the dosage of diazepam above $40 \mathrm{mg} / \mathrm{kg}$ per day did not appreciably reduce the need for subsequent respiratory support, as 6 of the 7 patients requiring more than $40 \mathrm{mg} / \mathrm{kg}$ per day needed IPPV (Table).

The main side effects encountered with this regimen were severe drowsiness, coma, and occasionally apnoeic episodes which were reversible when the dose of the drug was reduced. These patients tended to have excessive pooling of secretions in the oropharynx because the swallowing reflex was depressed, and they required frequent suction. Respiratory arrest is another potential hazard, but the continuous infusion of diazepam did not seriously depress respiration. Renal, hepatic, and haematological functions were also unaffected.
Although diazepam forms a white precipitate when diluted with dextrose saline solutions, this does not result in any adverse reaction nor does it reduce the therapeutic potency (Smith and Masotti, 1971). However, the solvent of diazepam contains $5 \%$ sodium benzoate which competes with bilirubin for the binding sites in albumin, thus increasing the risks of hyperbilirubinaemia (Schiff et al., 1971). Hyperbilirubinaemia was not a problem as most of our patients were term infants and more than 7 days old at admission. In this series only 3 developed neonatal jaundice; the maximum total bilirubin levels reached were $8 \cdot 5,10 \cdot 8$, and (Case 15$) 18.2 \mathrm{mg} /$ $100 \mathrm{ml}$ respectively. Case 15 was treated with phototherapy and serum bilirubin fell to $10.8 \mathrm{mg} /$ $100 \mathrm{ml} 4$ days later; unfortunately this patient was lost to follow-up. During intravenous diazepam treatment, care was taken to ensure that the percutaneous intravenous needle was not dislodged as skin necrosis can result from subcutaneous perfusion of the drug.

\section{References}

Femi-Pearse, D. (1966). Experience with diazepam in tetanus. British Medical Journal, 2, 862-865.

Ganendran, A. (1974). Intensive therapy in neonatal tetanus. Anaesthesia, 29, 356-362.

Hendrickse, R. G., and Sherman, P. M. (1966). Tetanus in childhood: report of a therapeutic trial of diazepam. British Medical Journal, 2, 860-862.

Lee, E. L., Khoo, B. H., and Lam, K. L. (1978). The management of neonatal tetanus. Medical Journal of Malaysia, 32, 220-224.

Oduori, M. L. (1974). Experience in the management of tetanus neonatorum with particular reference to the role of diazepam. East African Medical Journal, 51, 33-43.

Patel, J. C., and Joag, C. G. (1959). Grading of tetanus to evaluate prognosis. Indian Journal of Medical Sciences, 13, 834-840.

Randal, L. O., Herse, G. A., Schallak, W., Bagdon, R. E., Banziger, R., Boris, A., Moe, R. A., and Abrams, W. B. (1961). Pharmacological and clinical studies on valium, a new psychotherapentric agent of the benzodiazepine class. Current Therapeutic Research, 3, 405-425.

Schiff, D., Chan, G., and Stern, L. (1971). Fixed drug combinations and the displacement of bilirubin from albumin. Pediatrics, 48, 139-140.

Smith, B. T., and Masotti, R. E. (1971). Intravenous diazepam in the treatment of prolonged seizures in infants and children. Developmental Medicine and Child Neurology, 13, 630-634.

Correspondence to Dr B. H. Khoo, Department of Paediatrics, University Hospital, Kuala Lumpur, Malaysia. 